\title{
Total lipid in the broodstock diet did not affect fatty acid composition and quality of eggs from sea bass (Dicentrarchus labrax L.)*
}

\author{
JOSÉ M ${ }^{\mathrm{a}}$. NAVAS ${ }^{1}$, MARK THRUSH ${ }^{2}$, SILVIA ZANUY ${ }^{1}$, JESÚS RAMOS ${ }^{1}$, \\ NIALL BROMAGE ${ }^{2}$ and MANUEL CARRILLO ${ }^{1 \dagger}$ \\ ${ }^{1}$ Instituto de Acuicultura de Torre de la Sal (CSIC), 12595-Torre de la Sal, Castellón, Spain. \\ ${ }^{2}$ Institute of Aquaculture, University of Stirling, FK9 4LA, Scotland, UK.
}

\begin{abstract}
SUMMARY: To determine whether an increase in the quantity of lipids ingested by sea bass (Dicentrarchus labrax) broodstock could improve egg quality, three year-old sea bass were fed three different diets: a natural diet (Control group), and two artificial diets containing $10 \%$ or $17 \%$ of total lipids. In two consecutive reproductive seasons, the spawning results, the lipid classes and the fatty acid composition of the eggs were studied. No differences in the absolute content of lipids or in the percentage of different lipid classes were observed between the eggs from the three groups. Both experimental groups fed with the artificial diets produced eggs of poor quality, with low percentages of buoyancy and hatching. Those observed in the eggs from the Control Group were significantly higher $(\mathrm{p}>0.01)$ than those of the experimental groups. The higher hatching rate of the eggs from the Control Group was associated with higher DHA:EPA and AA:EPA ratios. The data obtained showed that the fatty acid composition of the eggs was affected by the fatty acid composition of the diets but not by the total quantity of lipids administered to the broodstock.
\end{abstract}

Key words: Fish, teleost, sea bass, fatty acids, docosahexaenoic, eicosapentaenoic, reproduction, diet.

\section{INTRODUCTION}

Food quality is accepted as one of the most important factors in determining spawning performance and subsequent egg quality in fish. Although different parameters have been used to determine egg quality, in the present work this term refers to egg buoyancy and hatching rates. Several studies have investigated the influence of diet composition on spawning performance and egg and larval quality (Luquet and Watanabe, 1986; Kjorsvik et al., 1990;

\footnotetext{
Corresponding author: E-mail: carrillo@iats.csic.es

*Received June 16, 1999. Accepted September 21, 2000.
}

Bromage et al., 1992). In particular, the lipidic fraction of the diets has been shown to exert a clear influence on egg viability. Studies carried out on rainbow trout, Oncorhynchus mykiss (Watanabe et al., 1984), red sea bream, Pagrus major (Watanabe et al., 1991), and gilthead sea bream, Sparus aurata (Zohar et al., 1995), demonstrated that ovarian and embryonic development were greatly affected by the fatty acid composition of the diet. All these experiments showed that it was necessary to provide an adequate quantity of n-3 fatty acids to prevent low hatching rates and poor larval survival. Some n-3 fatty acids, the highly unsaturated fatty acids (HUFA) eicosapentaenoic acid (EPA, 20:5 n-3) and docosa- 
hexaenoic acid (DHA, 22:6 n-3) play a key role as components of the phospholipids of biomembranes (Sargent et al., 1995). However, greater importance has been attributed to DHA in embryonic development than to EPA (Watanabe, 1993), as DHA is very abundant in brain and retinal cell membranes where its deficiencies can produce abnormal larval development (Sargent et al., 1995) and lead to very low percentages of hatching and larval survival. The marine fish species studied to date do not seem to be able to elongate and desaturate their $\mathrm{C} 18$ precursor, linolenic acid (18:3 n-3), to EPA and DHA (Sargent et al., 1995), due to a deficiency in the enzyme $\Delta 5$ desaturase. Consequently, both DHA and EPA are essential for marine fish and need to be supplied in the diet. Moreover, the ability of marine fish to convert EPA to DHA is very limited (Tocher et al., 1992; Mourente and Tocher, 1993) and it is necessary to consider the optimal dietary DHA:EPA ratio to satisfy the requirement of DHA. Therefore, additional work is needed to establish the most suitable ratio between these two fatty acids.

Although several studies have emphasised the importance of n-3 fatty acids for embryonic development, few of them have investigated the role played by the $n-6$ fatty acids. Of these, arachidonic acid (AA, 20:6 n-6) is of great importance for embryonic development, as it is the major precursor of eicosanoids in fish and mammals (Sargent et al., 1995). Recently, it has been shown that this fatty acid is essential for the production of prostaglandins in juvenile turbot, Scophthalmus maximus, and its deficiency could lead to abnormal development and growth of the fish (Bell et al., 1995). One of the n-3 fatty acids, EPA, can also be converted to prostaglandins and competes with AA for the same enzyme systems, so an inadequate AA:EPA ratio could lead to an abnormal eicosanoid production. However, few studies have taken into account the AA:EPA ratio to explain the influence of the fatty acid composition of the eggs on their quality.

In the sea bass (Dicentrarchus labrax), Cerdá et al. (1995) reported dramatic reductions of fecundity and egg viability in broodstock fed with an artificial diet deficient in n-3 PUFA (polyunsaturated fatty acids, i.e. fatty acids with more than one double bound), when compared with fish fed with a natural diet composed of trash fish. In further experiments, we have observed that the egg quality is greatly influenced by the fatty acid content of the lipid fraction of formulated diets and in particular by the n3:n-6 ratio (Navas et al., 1997). Bell et al. (1997) analysed the fatty acid content of the eggs from sea bass broodstock fed with two formulated diets and with a natural diet. They suggested that the marked differences observed in the AA:EPA ratios of the eggs could be related to differences in their quality, but no data about spawning performance were added. When broodstock seabass were fed with two formulated diets enriched in HUFA, it was observed that the higher AA:EPA and DHA:EPA ratios from one of the diets were reflected in the fatty acid composition of the eggs and were associated with the highest egg viability and hatching rates (Bruce et al., 1999).

The work presented in this article was the first of a set of experiments devoted to observing the influence of the fatty acid composition of the diet on the reproductive performance of the sea bass (see also Navas et al., 1997; Navas et al., 1998). Our initial hypothesis was that a high lipid content in the artificial diets could provide a sufficient quantity of different classes of fatty acids, particularly n-3 fatty acids, to improve the spawning performance of sea bass, which was reported to be very low in fish fed with artificial diets poor in n-3 fatty acids. A natural diet, which previously induced good spawning results in the sea bass (Cerdá et al., 1995), served as a positive control.

\section{MATERIAL AND METHODS}

\section{Broodstock and experimental diets}

Seventy-five male and female 3-year-old sea bass (mean weight and length: $567.8 \pm 20.3 \mathrm{~g}$ and $35.7 \pm 0.35 \mathrm{~cm}$ respectively) were reared at the Instituto de Acuicultura de Torre de la Sal (east coast of Spain, $40^{\circ} \mathrm{N}, 0^{\circ}$ ). At the beginning of the summer, the fish were divided into three groups. Each group contained 24-26 fish and the male-female ratio varied from 1:1 to 2:1. They were kept in 20001 tanks supplied with aerated flow-through $\left(21 . \mathrm{min}^{-1}\right)$ sea water and at ambient temperature and photoperiod for two years.

Two groups of broodstock were fed experimental pelleted diets ( $9 \mathrm{~mm}$ pellet, BOCM Pauls, Renfrew, Scotland) containing 10\% lipids (Group A) and 17\% lipids (Group B). The composition of these diets was provided by the manufacturer, who controlled it regularly. The third group was fed solely on trash fish (Boops boops) and provided the Control Group for this experiment. Samples of all the diets were taken approximately every three months, the basic 
TABLE 1. - Percentages of raw materials used in the manufacture of the $10 \%$ lipid diet. To obtain the $17 \%$ lipid diet, $15 \%$ of fish oil was added, and the percentages of the other components were proportionally reduced.

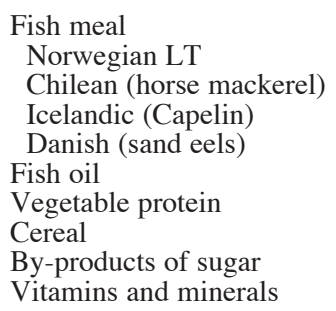

Sea bass are pelagic spawners and females and males release their ova and sperm spontaneously into the tanks. During the course of two successive spawning seasons, naturally fertilised eggs were collected daily on fine meshed screens placed across the tank outflows. Different spawnings from the same tank could be easily recognised by observing the developing stage of the embryo. The number of spawnings per female was calculated at the end of the spawning period. The eggs were transferred into a graduated cylinder to record the volume of viable (floating) and non-viable (sinking) eggs, as previ-

TABLE 2. - Proximate composition (percentage of dry weight) of the pelleted diets and the natural diet (trash fish, Boops boops) used to feed the Control Group.

\begin{tabular}{lccc}
\hline & Wet fish & $\begin{array}{c}\text { Diets } \\
\text { 10\% lipid pellets }\end{array}$ & $17 \%$ lipid pellets \\
\hline Dry weight (\%) & 23 & 91 & 92 \\
Proteins & 71 & 60 & 55 \\
Carbohydrates & Not detected & 19 & 17 \\
Lipids & 9 & 10 & 17 \\
Ash & 9 & 10 & 11 \\
\hline
\end{tabular}

composition of the trash fish was analysed, and fatty acid analysis of the lipidic fraction of the samples was also carried out.

The animals were fed five days a week at a ration of $2.2 \%$ tank biomass per day, from June to October, and $1.2 \%$ the rest of the year. The amount of feed given to each group of broodstock was adjusted monthly, after sampling. The raw materials used in the pelleted diets are shown in Table 1 . The proximate composition of the diets used in this experiment is shown in Table 2 . The fatty acid composition of the dietary lipid is shown in Table 3.

\section{Data collection, egg sampling and incubation}

The animals were sampled at monthly intervals until the beginning of the second spawning season. Before sampling, the fish were anaesthetised with ethyl m-aminobenzoate methanesulfonate (MS-222. 0.1 g. $1^{-1}$ ) after one day of starvation. Length and weight were recorded and the tank biomass was calculated in order to adjust the ration for each experimental group. During the second spawning season, animals were not sampled to avoid any possible deleterious effects of fish manipulation on spawning performance, but they were sampled at the end of the second spawning season to record female weights for calculation of relative fecundity.
TABLE 3. - Fatty acid composition of the natural diet (trash fish) used to fed the control group, and the pelleted diets used for the experimental groups: A (10\% lipid) and B (17\% lipid).

\begin{tabular}{|c|c|c|c|}
\hline & $\begin{array}{c}\text { Trash fish diet } \\
\text { (Control) }\end{array}$ & $\begin{array}{l}10 \% \text { total } \\
\text { lipid diet } \\
\text { (Group A) }\end{array}$ & $\begin{array}{l}\text { 17\% total } \\
\text { lipid diet } \\
\text { (Group B) }\end{array}$ \\
\hline $14: 0$ & 1.9 & 4.1 & 4.4 \\
\hline $15: 0$ & 0.7 & 0.4 & 0.4 \\
\hline $16: 0$ & 20.1 & 16.5 & 15.6 \\
\hline $16: 1 \mathrm{n}-7$ & 4.1 & 6.4 & 7.1 \\
\hline $16: 2 n-3$ & 0.7 & 0.9 & 0.8 \\
\hline $17: 0$ & 1.0 & 0.2 & 0.2 \\
\hline $16: 3 n-3$ & 0.6 & 0.4 & 0.4 \\
\hline $18: 0$ & 8.3 & 3.3 & 2.6 \\
\hline $18: 1 *$ & 10.7 & 16.7 & 15.1 \\
\hline $18: 2 n-6$ & 2.6 & 4.7 & 3.5 \\
\hline $18: 3 n-3$ & 0.6 & 1.1 & 1.1 \\
\hline $18: 4 n-3$ & 0.5 & 2.0 & 2.6 \\
\hline $20: 1 *$ & 1.8 & 8.2 & 10.9 \\
\hline $20: 4$ n-6 (AA) & 4.6 & 0.9 & 0.6 \\
\hline $20: 4 n-3$ & 0.2 & 0.6 & 0.6 \\
\hline $20: 5$ n-3 (EPA) & 6.7 & 9.0 & 9.0 \\
\hline $22: 1$ & 0.6 & 8.6 & 11.0 \\
\hline $22: 5 n-6$ & 1.2 & 0.1 & nd \\
\hline $22: 5 n-3$ & 2.4 & 1.5 & 1.2 \\
\hline 22:6 n-3 (DHA) & 22.1 & 10.9 & 10.0 \\
\hline Total saturates & 32 & 24.5 & 23.2 \\
\hline Total monoenes & 17.2 & 39.9 & 44.1 \\
\hline Total dienes & 3.3 & 5.6 & 4.3 \\
\hline Total PUFA & 42.2 & 32.1 & 29.8 \\
\hline Total n-3 & 33.8 & 26.4 & 25.7 \\
\hline Total n-6 & 8.4 & 5.7 & 4.1 \\
\hline$n-3: n-6$ ratio & 4.0 & 4.6 & 6.3 \\
\hline AA: EPA ratio & 0.6 & 0.1 & 0.1 \\
\hline DHA : EPA ratio & 3.3 & 1.2 & 1.1 \\
\hline
\end{tabular}

Values are expressed as percentages of the lipid content of the diet. * Includes more than one monoene. 
ously described (Carrillo et al., 1989). From these volumes, the total number of viable and non-viable eggs in each spawn was calculated using the formula: $\mathrm{N}=2865-1796 \mathrm{D}$ (where $\mathrm{N}=$ the number of eggs in $1 \mathrm{ml}$, and $\mathrm{D}=$ the mean diameter of 100 eggs). This formula corresponds to the regression line obtained when, in 25 different spawnings, the mean diameter of 100 eggs was related to the number of eggs observed in $1 \mathrm{ml}\left(\mathrm{r}^{2}=0.94\right)$ (Navas et al., 1998). The total fecundity (TF) of each group was calculated as the number of eggs collected during the entire spawning period divided by the number of females. The relative fecundity (RF) was calculated as the number of eggs collected during the entire spawning period divided by the total post-spawning body weight of the females. Three aliquots of viable eggs $(1 \mathrm{ml})$ were transferred to incubators to determine the survival to hatch. The incubators consisted of $20 \mathrm{~cm}$ diameter polyvynylchloride (PVC) cylinders fitted with a nylon bottom mesh and partially submerged in a large tank. The system was provided with slow-flowing and aerated seawater and the water temperature was $16 \pm 2^{\circ} \mathrm{C}$. Under these conditions, hatching took place approximately $72 \mathrm{~h}$ later. After this period the number of non-hatched eggs and of new larvae was observed in the nylon mesh of the cylinder. The percentages of egg viability and the hatching rates were assessed at the end of the experimental period from all the data collected.

\section{Lipid analysis}

Duplicate samples of 100 eggs from each spawning were stored in 10 volumes of chloroform/methanol $(2: 1 \mathrm{v} / \mathrm{v})$ with $0.01 \%(\mathrm{w} / \mathrm{v})$ butylated hydroxytoluene (BHT) at $-70^{\circ} \mathrm{C}$ prior to extraction. The samples were then homogenised in chloroform/methanol $(2: 1 \mathrm{v} / \mathrm{v})$. Total lipid was extracted using the method of Folch et al., (1957) and weights were determined gravimetrically using an Ohaus JA200B analytical balance.

Lipid classes were analysed according to the double development high-performance thin layer chromatography (HPTLC) method described by Olsen and Henderson (1989) using 10 x $10 \mathrm{~cm}$ silica gel plates (E. Merck, Darmstadt, Germany). The solvent systems used to develop polar lipid (PL) and neutral lipid (NL) classes were methyl acetate: propan-2-ol: chloroform: methanol: $0.25 \%$ aq. $\mathrm{KCl}$ (25:25:25:10:9 by volume) and hexane: diethyl ether: acetic acid (80:20:2 by volume) respectively. The plates were then sprayed with copper acetate/phosphoric acid reagent (Fewster et al., 1969) and charred at $160^{\circ} \mathrm{C}$ for 120 minutes, before analysis by quantitative scanning densitometry using a Shimadzu CS9000 densitometer.

Fatty acid methyl esters were prepared by transesterification of $250 \mathrm{mg}$ of total lipid with $1 \%$ sulphuric acid in methanol and toluene $(2: 1 \mathrm{v} / \mathrm{v})$ at $50^{\circ} \mathrm{C}$ for $16 \mathrm{~h}$ (Christie, 1982). These were purified by thin layer chromatography (TLC) prior to analysis using a Packard 436 gas chromatograph, as detailed by Tocher et al. (1985).

\section{Statistical analysis}

Values are expressed as average \pm SEM. Statistical differences in the percentage rates of egg viability and hatching between groups were tested using a Kruskal-Wallis non-parametric analysis of variance followed by Dunn's multiple comparisons test. Nonparametric data were assessed using the test of Kolmogorov-Smirnov for normality of distribution and Bartlet's test for homogeneity. Percentages of lipid class and of fatty acids were compared between groups using one-way analysis of variance (ANOVA) followed by the multiple range "t-test" for parametric data and a Kruskal-Wallis test for non-parametric data.

\section{RESULTS}

\section{Spawning characteristics}

The female weights and lengths did not show differences between groups during the period in which these data were recorded (data not shown). The results of spawning performance of the broodstock sea bass fed with a natural diet (Control Group) and with the artificial diets (Groups A and B) are summarised in Table 4. In both spawning seasons, the Control Group showed the highest percentage of viable eggs (buoyant eggs), being statistically different $(p<0.01)$ to those observed in Groups A and $\mathrm{B}$. Regarding the hatching rates, the Control Group exhibited significantly higher values $(p<0.01)$ than Groups A and B in the first spawning season, whereas in the second spawning season the values in the Control Group were not significantly different from those of Group A, and in Group B the hatching rate was equal to zero. In both spawning seasons, the total fecundity (TF) was higher in the Control Group than in Groups A and B. In the second spawning 
TABLE 4. - Percentages of buoyant eggs and of hatching and values of total fecundity (TF) and relative fecundity (RF) obtained from the groups fed with a natural diet (Control) and with experimental diets (A and B).

\begin{tabular}{|c|c|c|c|c|}
\hline & $\begin{array}{l}\text { Spawning } \\
\text { Season }\end{array}$ & $\begin{array}{l}\text { Control } \\
\text { Trash fish }\end{array}$ & $\begin{array}{l}\text { Group A } \\
10 \% \text { lipids }\end{array}$ & $\begin{array}{l}\text { Group B } \\
17 \% \text { lipids }\end{array}$ \\
\hline Buoyant eggs & $1^{\text {st }}$ & $57.6 \pm 7.0^{\mathrm{a}}$ & $18.5 \pm 4.0^{b}$ & $10.2 \pm 2.4^{b}$ \\
\hline (\% from total eggs) & $2^{\text {nd }}$ & $46.5 \pm 9.3^{a}$ & $7.4 \pm 4.4 \mathrm{~b}$ & $2.0 \pm 1.8^{b}$ \\
\hline Hatching rate & $1^{\text {st }}$ & $14.6 \pm 4.7^{\mathrm{a}}$ & $1.3 \pm 0.9^{b}$ & $0.8 \pm 0.5^{b}$ \\
\hline (\% from viable eggs) & $2^{\text {nd }}$ & $26.7 \pm 8.5^{a}$ & $9.2 \pm 4.0^{a}$ & $0.0 \pm 0.0^{b}$ \\
\hline \multirow[t]{2}{*}{ Total fecundity } & $1^{\text {st }}$ & 685867 & 622156 & 404021 \\
\hline & $2^{\text {nd }}$ & 714299 & 569171 & 547633 \\
\hline \multirow[t]{2}{*}{ Relative fecundity } & $1^{\text {st }}$ & 690702 & 668505 & 420823 \\
\hline & $2^{\text {nd }}$ & 490365 & 381994 & 267411 \\
\hline
\end{tabular}

Diferent letters (superscripts) indicate significant differences $(\mathrm{p}<0.01)$ between groups within the same spawning season.

TABLE 5. - Percentage lipid class composition of the total lipid extracted from fertilized eggs of sea bass reared on different diets during the first and second spawning seasons. No differences were observed between groups in the mean content of each lipid class within a particular spawning season.

\begin{tabular}{|c|c|c|c|c|c|c|}
\hline \multirow[b]{3}{*}{ Total lipid ( $\mu$ g per egg) } & \multicolumn{3}{|c|}{ First spawning season } & \multicolumn{3}{|c|}{ Second spawning season } \\
\hline & Control & Group A & Group B & Control & Group A & Group B \\
\hline & $52.3 \pm 4.6$ & $67.5 \pm 8.8$ & $50.0 \pm 5.1$ & $47.7 \pm 5.9$ & $53.5 \pm 6.5$ & $49.7 \pm 9.4$ \\
\hline \multicolumn{7}{|c|}{ Lipid class composition (\% of total lipid) } \\
\hline Sphingomyelin & $0.1 \pm 0.0$ & $0.1 \pm 0.0$ & $0.5 \pm 0.1$ & $0.5 \pm 0.1$ & $0.2 \pm 0.1$ & $0.5 \pm 0.1$ \\
\hline Phosphatidylcholine & $10.7 \pm 2.6$ & $6.9 \pm 1.1$ & $14.0 \pm 0.7$ & $13.1 \pm 0.6$ & $12.5 \pm 0.6$ & $12.0 \pm 1.3$ \\
\hline Phosphatidylinositol & $0.8 \pm 0.2$ & $0.6 \pm 0.0$ & $0.8 \pm 0.1$ & $1.3 \pm 0.1$ & $1.1 \pm 0.1$ & $1.2 \pm 0.1$ \\
\hline Phosphatidylethanolamine & $3.2 \pm 0.9$ & $2.9 \pm 0.7$ & $3.3 \pm 0.1$ & $4.3 \pm 0.2$ & $3.8 \pm 0.2$ & $3.7 \pm 0.5$ \\
\hline Neutral lipids & $83.7 \pm 5.5$ & $87.6 \pm 8.4$ & $84.6 \pm 5.2$ & $80.6 \pm 5.3$ & $81.9 \pm 6.3$ & $82.0 \pm 7.7$ \\
\hline
\end{tabular}

Values are expressed as mean \pm SEM. $n=5$.

season, the TF increased in the Control Group and Group B. The relative fecundity (RF) was higher in the Control Group than in Groups B and C in both spawning seasons, although in the second spawning season a clear reduction of this parameter was observed in the three groups.

\section{Lipid class composition of the eggs}

The lipid class composition of the eggs obtained from the three groups in the first and second spawning seasons are summarised in Table 5. No significant differences between groups were detected in the lipid class composition of the eggs. The predominant components of the egg lipids were neutral lipids $(83 \%$ to $88 \%)$. Among the polar lipids, phosphatidylcholine ( $7 \%$ to $14 \%$ ) had the highest percentage in the eggs from all the groups in both spawning seasons studied, followed by phosphatidylethanolamine (3\% to $4 \%$ ).

\section{Fatty acid composition of the eggs}

The fatty acid composition of the eggs of the three experimental groups in the first and second spawning seasons is shown in Table 6. In the first spawning season, the Control Group had the lowest percentage of linoleic acid (18:2 n-6), although no statistical differences were observed between the groups. The highest percentage of AA was observed in the Control Group, but it was only significantly different $(\mathrm{p}<0.05)$ from that of group A. No significant differences were observed between groups in the egg content of DHA or EPA. However, the Control Group exhibited the lowest percentage of EPA, and therefore, the DHA:EPA and AA:EPA ratios in this group were significantly higher $(p<0.05)$ than in groups $\mathrm{A}$ and $\mathrm{B}$.

In the second spawning season, after a longer period of dietary treatment, the differences in the egg fatty acid content between the groups were accentuated. The percentage of linoleic acid in the Control Group was significantly lower $(p<0.05)$ than in the experimental groups, and Group B had significantly lower levels $(\mathrm{p}<0.05)$ of this fatty acid than Group A. The quantity of linolenic acid (18:3 $n-3)$ in the Control Group was the lowest $(\mathrm{p}<0.05)$, but this group exhibited the highest $(p<0.05)$ levels of AA. Simultaneously, the percentage of AA in Group B was significantly higher $(p<0.05)$ than in Group A. In the Control Group, the percentage of EPA was the lowest $(\mathrm{p}<0.05)$, and this group had the 
TABLE 6. - Fatty acid composition of the total lipid extracted from fertilised eggs of sea bass reared on different diets during the first and second spawning seasons. Significant differences $(\mathrm{p}<0.05)$ between fatty acid concentrations in the eggs of different groups into a particular spawning season were signalled by different superscripts ( $\mathrm{a}, \mathrm{b}$ and $\mathrm{c}$ ). Means with superscript 'a' are significantly different from means with superscript ' $b$ ' and from means with superscript ' $c$ '. In the same way, means with superscript 'ab' are not significantly different from means with superscript 'a' or from means with superscript ' $b$ '. If no significant differences were found, no superscripts are presented.

\begin{tabular}{|c|c|c|c|c|c|c|}
\hline & \multicolumn{3}{|c|}{ First spawning season } & \multicolumn{3}{|c|}{ Second spawning season } \\
\hline & Control & Group A & Group B & Control & Group A & Group B \\
\hline $14: 0$ & $2.0 \pm 0.0$ & $2.4 \pm 0.3$ & $2.3 \pm 0.1$ & $1.8 \pm 0.2$ & $2.0 \pm 0.1$ & $2.1 \pm 0.3$ \\
\hline $15: 0$ & $0.7 \pm 0.0$ & nd \pm 0.1 & $0.8 \pm 0.1$ & $0.5 \pm 0.1$ & $0.2 \pm 0.1$ & $0.3 \pm 0.1$ \\
\hline $16: 0$ & $17.0 \pm 0.7$ & $16.6 \pm 0.8$ & $14.9 \pm 0.2$ & $12.9 \pm 0.2$ & $13.4 \pm 1.2$ & $12.6 \pm 0.3$ \\
\hline $16: 1 *$ & $11.3 \pm 1.1$ & $10.6 \pm 0.2$ & $11.3 \pm 0.3$ & $8.8 \pm 0.3$ & $9.0 \pm 0.3$ & $9.0 \pm 0.1$ \\
\hline $16: 2 n-3$ & $1.6 \pm 0.1$ & $1.4 \pm 0.1$ & $0.9 \pm 0.1$ & $1.1 \pm 0.3^{\mathrm{a}}$ & $0.3 \pm 0.0^{\mathrm{b}}$ & $0.4 \pm 0.1^{\mathrm{c}}$ \\
\hline $17: 0$ & $0.8 \pm 0.1$ & nd & $0.3 \pm 0.0$ & $0.5 \pm 0.1^{a}$ & $0.2 \pm 0.1^{\mathrm{b}}$ & $0.2 \pm 0.1^{b}$ \\
\hline $16: 3 n-3$ & $1.9 \pm 0.1$ & $0.4 \pm 0.2$ & $0.4 \pm 0.1$ & $1.1 \pm 0.1^{\mathrm{a}}$ & $0.5 \pm 0.1^{b}$ & $0.7 \pm 0.1^{\mathrm{c}}$ \\
\hline $18: 0$ & $5.8 \pm 0.3$ & $5.3 \pm 0.2$ & $5.1 \pm 0.7$ & $4.2 \pm 0.1$ & $4.0 \pm 0.2$ & $4.0 \pm 0.2$ \\
\hline $18: 1 *$ & $31.6 \pm 0.5$ & $31.2 \pm 2.7$ & $28.7 \pm 0.8$ & $23.3 \pm 0.5^{\mathrm{a}}$ & $27.7 \pm 0.4^{b}$ & $25.5 \pm 0.1^{\mathrm{c}}$ \\
\hline $18: 2 n-6$ & $2.8 \pm 0.1$ & $6.7 \pm 0.5$ & $4.8 \pm 0.3$ & $1.8 \pm 0.2^{\mathrm{a}}$ & $6.8 \pm 0.1^{b}$ & $5.7 \pm 0.1^{\mathrm{c}}$ \\
\hline $18: 3 n-3$ & $0.9 \pm 0.1$ & $0.5 \pm 0.1$ & $0.9 \pm 0.1$ & $0.8 \pm 0.1^{a}$ & $1.1 \pm 0.1^{\mathrm{b}}$ & $1.2 \pm 0.1^{b}$ \\
\hline $18: 4 n-3$ & nd & nd & $0.3 \pm 0.1$ & $0.6 \pm 0.0^{a}$ & $0.7 \pm 0.1^{\mathrm{a}}$ & $1.0 \pm 0.1^{b}$ \\
\hline $20: 1 *$ & $1.2 \pm 0.2$ & $3.0 \pm 0.5$ & $1.8 \pm 0.2$ & $1.1 \pm 0.1^{a}$ & $2.8 \pm 0.0^{b}$ & $3.1 \pm 0.0^{\mathrm{c}}$ \\
\hline $20: 4$ n-6 (AA) & $2.0 \pm 0.3^{a}$ & $0.5 \pm 0.1^{b}$ & $1.0 \pm 0.2^{a b}$ & $1.9 \pm 0.1^{a}$ & $0.9 \pm 0.1^{b}$ & $1.1 \pm 0.0^{\mathrm{c}}$ \\
\hline $20: 4 n-3$ & $0.6 \pm 0.2$ & $0.2 \pm 0.0$ & $0.5 \pm 0.1$ & $0.6 \pm 0.1^{a}$ & $0.5 \pm 0.0^{b}$ & $0.7 \pm 0.1^{\mathrm{c}}$ \\
\hline $20: 5$ n-3 (EPA) & $1.4 \pm 0.1$ & $3.3 \pm 0.1$ & $4.5 \pm 0.3$ & $5.7 \pm 0.2^{a}$ & $7.1 \pm 0.1^{b}$ & $7.2 \pm 0.1^{b}$ \\
\hline $22: 1$ & $\mathrm{nd}^{\mathrm{a}}$ & $0.8 \pm 0.1^{b}$ & $0.9 \pm 0.2^{b}$ & nd $^{\mathrm{a}}$ & $0.8 \pm 0.1^{b}$ & $0.9 \pm 0.1^{b}$ \\
\hline $22: 5 n-6$ & $0.7 \pm 0.1^{a}$ & $\mathrm{nd} \pm 0.1$ & $0.1 \pm 0.1$ & $0.8 \pm 0.1^{a}$ & $0.1 \pm 0.1^{b}$ & $0.3 \pm 0.1^{b}$ \\
\hline $22: 5 n-3$ & $0.8 \pm 0.1$ & $0.3 \pm 0.1$ & $1.0 \pm 0.1$ & $1.8 \pm 0.1^{\mathrm{a}}$ & $1.3 \pm 0.1^{\mathrm{b}}$ & $1.5 \pm 0.1^{b}$ \\
\hline $22: 6$ n-3 (DHA) & $9.0 \pm 0.1$ & $10.5 \pm 0.9$ & $12.9 \pm 0.6$ & $28.0 \pm 0.7^{a}$ & $17.4 \pm 0.2^{b}$ & $19.5 \pm 0.1^{\mathrm{c}}$ \\
\hline Total saturates & $26.3 \pm 0.5$ & $24.3 \pm 0.9$ & $23.4 \pm 0.5$ & $19.9 \pm 0.5$ & $19.8 \pm 0.5$ & $19.2 \pm 0.1$ \\
\hline Total monoenes & $44.1 \pm 1.4$ & $45.1 \pm 0.5$ & $42.7 \pm 2.2$ & $33.2 \pm 0.4^{\mathrm{a}}$ & $40.3 \pm 0.8^{b}$ & $38.5 \pm 0.3^{c}$ \\
\hline Total dienes & $4.4 \pm 0.1$ & $8.1 \pm 0.7$ & $5.7 \pm 0.1$ & $2.9 \pm 0.1^{\mathrm{a}}$ & $7.1 \pm 0.3^{b}$ & $6.1 \pm 0.1^{\mathrm{c}}$ \\
\hline Total PUFA & $21.7 \pm 1.1$ & $23.8 \pm 0.9$ & $27.3 \pm 0.4$ & $44.2 \pm 1.4^{\mathrm{a}}$ & $36.7 \pm 0.4^{b}$ & $39.3 \pm 0.6^{c}$ \\
\hline Total n-3 & $16.2 \pm 0.5$ & $16.6 \pm 0.2$ & $21.4 \pm 0.7$ & $39.7 \pm 0.9^{a}$ & $28.9 \pm 0.7^{b}$ & $32.2 \pm 0.7^{\mathrm{c}}$ \\
\hline Total n-6 & $5.5 \pm 0.6$ & $7.2 \pm 0.9$ & $5.9 \pm 0.2$ & $4.5 \pm 0.6^{a}$ & $7.8 \pm 0.9^{b}$ & $7.1 \pm 0.6^{b}$ \\
\hline n-3 : n-6 ratio & $2.9 \pm 0.2$ & $2.3 \pm 0.1$ & $3.6 \pm 0.3$ & $8.8 \pm 0.2^{a}$ & $3.7 \pm 0.1^{b}$ & $4.5 \pm 0.1^{\mathrm{c}}$ \\
\hline AA : EPA ratio & $1.4 \pm 0.1^{a}$ & $0.1 \pm 0.0^{b}$ & $0.2 \pm 0.0^{b}$ & $0.3 \pm 0.1$ & $0.1 \pm 0.0$ & $0.1 \pm 0.0$ \\
\hline DHA : EPA ratio & $6.4 \pm 0.2^{a}$ & $3.2 \pm 0.1^{b}$ & $2.9 \pm 0.1^{b}$ & $4.9 \pm 0.1^{\mathrm{a}}$ & $2.4 \pm 0.2^{b}$ & $2.7 \pm 0.1^{b}$ \\
\hline
\end{tabular}

Values are expressed as percentages of the lipid content of the eggs. $n=5$. $*$ Includes more than one monoene.

highest $(\mathrm{p}<0.05)$ DHA levels. The AA:EPA and DHA:EPA ratios were therefore significantly higher in the Control Group than in Groups A and B.

The amount of $\mathrm{n}-3$ fatty acids was significantly higher $(\mathrm{p}<0.05)$ in the eggs from the Control Group than in those from Groups A and B. Group B showed a significantly higher $(p<0.05)$ percentage of $n-3$ fatty acids than Group A. In contrast, the amount of n- 6 fatty acids was lower $(p<0.05)$ in the Control Group than in the rest of the groups. As a result of these differences, the n-3:n-6 ratio was significantly higher $(\mathrm{p}<0.05)$ in the Control Group than in the pelleted fed groups. However, this ratio was significantly higher $(\mathrm{p}<0.05)$ in Group B than in Group A.

\section{DISCUSSION}

This study shows that simple increments in the dietary amount of lipids administered to broodstock sea bass were not sufficient to induce an improvement in their reproductive performance. As will be discussed, other factors, particularly the proportion between different fatty acids, should have been taken into account in the design of the diets.

The egg buoyancy and hatching rates in the Groups A and B were lower than in the Control Group during both spawning seasons (Table 4). Also, unlike the Groups A and B, the prolonged dietary treatment in the Control Group led to a general improvement in its spawning performance, and a clear increase in the hatching rate was observed in the second spawning season. Since the first spawning season studied was the first for all the animals, it is possible that a better use of the dietary resources during the second spawning season could have contributed to the observed improvement in the spawning performance of the Control Group. Previous experiments in our laboratory have shown that during the first maturation and spawning the egg quality is lower than in successive sexual cycles (Cerdá et al., 1995; Carrillo et al., 2000).

The low hatching rates and fecundity in groups $\mathrm{A}$ and B cannot be attributed to dietary protein, since 
these experimental diets contained 55 and $60 \%$ of proteins respectively and in a previous work Cerdá et al., (1994) showed that a content of $51 \%$ of crude protein in the diets did not negatively affect fecundity or egg quality in the sea bass. This $51 \%$ protein diet exhibited a low content of carbohydrates and had no detrimental effects on egg quality. Therefore, the percentage of carbohydrates in the artificial diets used in this experiment appears to be high enough. On the other hand, some individual components of the diets such as micro-nutrients (i.e. amino acids, minerals, vitamins and fatty acids) affect the egg quality. Since the lipidic fraction of the diet, and in particular its fatty acid composition, play an essential role in determining spawning performance in fish, in the present work the lipid classes and the fatty acid composition of the eggs were analysed in order to determine whether these factors could have contributed to the differences in fecundity and hatching rates observed between the groups.

Spawning performance has been shown to be closely related to the n-3 fatty acid content of the eggs. In fishes, these fatty acids are very important for the maintenance of membrane fluidity, permeability and normal physiological functions of the membrane-bound enzymes (Bell et al., 1986). However, in addition to the absolute content of n-3 fatty acids, the n-3:n-6 ratio is also important for determining the quality of the egg (Bell et al., 1986). In the present experiment, the differences in the hatching rates between the Control Group and Groups A and $\mathrm{B}$ during the first spawning season were not associated with differences in the n-3 content of the eggs or in the n-3:n-6 ratio. However, in the second spawning season, a clear increase in the n-3 fatty acid content of the eggs was observed in all the experimental groups, which was particularly high in the Control Group and led to a higher n-3:n-6 ratio. This phenomenon could have contributed to the improvements in the hatching rate of the Control Group during the second spawning season and to the differences observed in the hatching rates between the Control Group and Groups A and B.

Among the n-3 fatty acids, the n-3 HUFA (i.e. DHA and EPA) play an essential role in maintaining the stability of biomembranes (Sargent et al., 1989). These two fatty acids are essential for marine fishes and need to be supplied by the diet (Sargent et al., 1989). However, in addition to the absolute values of DHA and EPA, their relative proportion is also very important. Several works (Watanabe et al., 1989a, b; Watanabe, 1993; Koven et al., 1993) have pointed out the greater importance of DHA over EPA for the correct development of fish embryos. Consequently, high EPA and low DHA levels can lead to low hatching rates and high mortality of larval fish (Sargent et al., 1995). In the present experiment, the higher DHA:EPA ratio observed in the eggs from the Control Group probably contributed to the higher hatching rates recorded in this group. The high lipid content of the artificial diets did not induce an increase in the DHA:EPA ratio of the eggs. Thus, the eggs from Groups A and B showed a lower DHA:EPA ratio, reflecting the lower DHA:EPA ratio of the artificial diets.

Though the importance of an adequate dietary supply of n-3 HUFA for the normal development of the marine fish eggs and larvae has been established, few studies have concentrated on the requirements of $\mathrm{n}-6$ fatty acids, particularly arachidonic acid (AA), 20: $4 \mathrm{n}-6$. AA is a precursor of eicosanoids, in particular those of the 2 series prostanoids and the 4 series leukotrienes, which have important physiological functions (Sargent et al., 1995). In particular, the series 2 prostaglandins play a very important role in the regulation of gonadotrophin secretion and in the modulation of ovulation (Eberdhardt and Kiesel, 1992). As has been reported in turbot (Bell et al., 1995), alterations in the levels of AA can lead to changes in prostaglandin production, which could induce physiological damage in the fish. However, EPA is itself a precursor of 3 series prostanoids and 5 series leukotrienes, although these are less biologically active than their homologues from series 2 and 4 derived from AA, and thus the EPA will competitively inhibit the production of eicosanoids from AA (Sargent et al., 1995). Consequently, the AA:EPA ratio exerts a profound influence on the production of eicosanoids and on the maintenance of normal physiological functions in fish. In a previous work on the sea bass, it was observed that the AA:EPA ratio in the different phospholipid classes was over 5 times higher in the eggs from fish fed on trash fish than fish fed a pelleted diet (Bell et al., 1997). However, no relationship was established in the sea bass between the AA:EPA ratio in the eggs and egg quality. In the present experiment, the quantity of AA in the eggs appeared to be directly related to the AA content of the diet, and the best spawning performance of the Control Group was associated with the highest egg AA content and AA:EPA ratio. Therefore, our observations agree with the hypothesis that the AA and AA:EPA ratio play an important role in determining the egg hatching rates. 
The low hatching rates observed in Groups A and B could also have been associated with the high concentration of long chain monounsaturated fatty acids detected in the artificial diets and in the eggs of these groups. In a previous work (Navas et al., 1998), it was observed that artificial diets with high lipid contents and high concentrations of long chain monounsaturated fatty acids induced very high levels of $17 ß$-estradiol in the plasma of broodstock. These high levels of 17ß-estradiol were associated with abnormal plasma levels of vitellogenin and gonado-grophin II, and with very low hatching rates. The long chain monounsaturated fatty acids are known as hepatic peroxisomal proliferators (Henderson and Sargent, 1985), and the peroxisomes are also present in the follicular cells of teleosts and are involved in steroidogenic processes (Mercure and Van der Kraak, 1995). Thus, the high concentrations of monounsaturated fatty acids in the artificial diets could have induced alterations in the normal synthesis of steroids, affecting the hormonal regulation of reproduction and contributing to the low hatching rates observed in Groups A and B.

In summary, the results presented here indicate that increased amount of lipids in the diet do not influence the fatty acid composition of the eggs, which is dependent on the dietary lipid fatty acid composition. Moreover, the egg quality is greatly influenced by the fatty acid composition of the eggs.

\section{ACKNOWLEDGEMENTS}

This work was supported in part by the EEC project FAR No AQ 2406 E UK to M. Carrillo. J.M. Navas received a $\mathrm{PhD}$ fellowship from the Generalitat Valenciana and a Marie Curie return fellowship contract N ${ }^{\circ}$ QOL-CT1999-1111.

\section{REFERENCES}

Bell, J., J.D. Castell, D.R. Tocher, F.M. MacDonald and J.R. Sargent. - 1995. Effects of different dietary arachidonic acid: docosahexaenoic acid ratios on phospholipid fatty acid compositions and prostaglandin production in juvenile turbot (Scophthalmus maximus). Fish Physiol. Biochem., 14: 139-151.

Bell, J.G., B.M. Farndale, M.P. Bruce, J.M. Navas and M. Carrillo. - 1997. Effects of broodstock dietary lipid on fatty acid composition of eggs from sea bass (Dicentrarchus labrax). Аquaculture, 149: 107-119.

Bell, M.V., R.J. Henderson and J.R. Sargent. - 1986. The role of polyunsaturated fatty acids in fish. Comp. Biochem. Physiol., 83(B): 711-719.

Bromage, N., J. Jones, C. Randall, M. Thrush, B. Davies, J. Springate, J. Duston and G. Barker. - 1992. Broodstock man- agement, fecundity, egg quality and the timing of egg production in the rainbow trout (Oncorhynchus mykiss). Aquaculture, 100: 141-166.

Bruce, M., F. Oyen, G. Bell, J.F. Asturiano, B. Farndale, M. Carrillo, S. Zanuy, J. Ramos and N. Bromage. - 1999. Development of broodstock diets for the European sea bass (Dicentrarchus labrax) with special emphasis on the importance of n-3 and n-6 HUFA to reproductive performance. Aquaculture, 177: 85-97.

Carrillo, M., N. Bromage, S. Zanuy, R. Serrano and F. Prat. - 1989. The effect of modification in photoperiod on spawning time, ovarian development and egg quality in the sea bass (Dicentrarchus labrax L.,). Aquaculture, 81: 351-365.

Carrillo, M., S. Zanuy, F. Oyen, J. Cerdá, J. M. Navas and J. Ramos. -2000 . Some criteria of the quality of the progenie as indicators of physiological broodstock fitness. In: CIHEAM (ed.), Recent advances in Mediterranean aquaculture finfish species diversification, pp. 61-74. Cahiers Options Méditerranées, 47.

Cerdá, J., M. Carrillo, S. Zanuy, J. Ramos and M. de la Higuera. 1994. Influence of nutritional composition of diet on the sea bass, Dicentrarchus labrax L., reproductive performance and egg and larval quality. Aquaculture, 128: 345-361.

Cerdá, J., S. Zanuy, M. Carrillo, J. Ramos and R. Serrano. - 1995. Short- and long-term dietary effects on female sea bass (Dicentrarchus labrax): seasonal changes in plasma profiles of lipids and sex steroids in relation to reproduction. Comp. Biochem. Physiol., 111(B): 83-91.

Christie,W.W. - 1982. Lipid Analysis. Pergamon Press, Oxford.

Eberdhardt, I. and L. Kiesel. - 1992. Role of arachidonic acid and lipoxigenase products in the mechanism of gonadotropin secretion: an update. Prostaglandins Leukotrienes Essent. Fatty Acids., 47: 239-246.

Fewster, M.E., B.J. Burns and J.F. Mesd. - 1969. Quantitative densitometric thin layer chromatography of lipids using copper acetate reagent. J. Chromatogr., 43: 120-126.

Folch, J., M. Lees and G.H. Sloane-Stanley. - 1957. A simple method for the isolation and purification of total lipids from animal tissues. J. Biol. Chem., 276: 497-509.

Henderson, R.J. and J.R. Sargent. - 1985. Chain-length specificities of mitochondrial and peroxisomal B-oxidation of fatty acids in livers of rainbow trout (Salmo gairdneri). Comp. Biochem. Physiol., 82(B): 79-85.

Kjorsvik, E., A. Mangor-Jensen and I. Holmefjord. - 1990. Egg quality in marine fishes. Adv. Mar. Biol., 26: 71-113.

Koven, W.M., A. Tandler, D. Sklan and G.W. Kissil. - 1993. The association of eicosapentaenoic and docosahexaenoic acids in the main phospholipids of different-age Sparus aurata larvae with growth. Aquaculture, 116: 71-82.

Luquet, P. and T. Watanabe. - 1986. Interaction "nutrition-reproduction" in fish. Fish Physiol. Biochem., 2: 121-129.

Mercure, F. and G. Van der Kraak. - 1995. Evidence for peroxisomal involvement in ovarian steroidogenesis in teleosts. In: F.W. Goetz and P. Thomas (eds.), Proceedings of the Fifth International Symposium on Reproductive Physiology of Fish. Fish Symp. 95, pp. 321. Austin, Texas.

Mourente, G. and D.R. Tocher. - 1993. Incorporation and metabolism of ${ }^{14} \mathrm{C}$-labelled polyunsaturated fatty acids in juvenile gilthead sea bream Sparus aurata L. in vivo. Fish Physiol. Biochem., 10: 443-453.

Navas, J.M., M. Bruce, M. Thrush, B.M. Farndale, N. Bromage, S. Zanuy, M. Carrillo, J.G. Bell and J. Ramos. - 1997. The impact of seasonal alteration in the lipid composition of broodstock diets on egg quality in the European sea bass (Dicentrarchus labrax L.). J. Fish Biol., 51: 760-773.

Navas, J.M., E. Mañanós, M. Thrush, J. Ramos, S. Zanuy, M. Carrillo, Y. Zohar and N. Bromage. - 1998. Effect of dietary lipid composition on vitellogenin, 17ß-estradiol and gonadotropin plasma levels and spawning performance in captive sea bass (Dicentrarchus labrax L.). Aquaculture, 165: 65-79.

Olsen, R.E. and R.J. Henderson. - 1989. The rapid analysis of neutral and polar marine lipids using double development HPTLC and scanning densitometry. J. Exp. Mar. Biol. Ecol., 129: 189-197.

Sargent, J.R., R.J. Henderson and D.R. Tocher. - 1989. The lipids. In: J.E. Halver (ed.), Fish Nutrition 2nd edn., pp. 153-218. Academic Press, San Diego.

Sargent, J.R., J.G. Bell, M.V. Bell., R.J. Henderson and D.R. Tocher. -1995 . Requirement criteria for essential fatty acids. $J$. Appl. Ichthyol., 11: 183-189.

Tocher, D.R., A.J. Fraser, J.R. Sargent and J.C. Gamble. - 1985. 
Fatty acid composition of lipids using double development HPTLC and scanning densitometry. J. Exp. Mar. Biol. Ecol., 129: $189-197$.

Tocher, D.R., G. Mourente and J.R. Sargent. - 1992. Metabolism of $\left[1-{ }^{14} \mathrm{C}\right]$ docosahexaenoate $(22: 6 \mathrm{n}-3),\left[1-{ }^{14} \mathrm{C}\right]$ eicosapentaenoate $(20: 5 \mathrm{n}-3)$ and $\left[1-{ }^{14} \mathrm{C}\right]$ linolenate $(18: 3 \mathrm{n}-3)$ in brain cells from juvenile turbot, Scophthalmus maximus. Lipids, 27: 494-499.

Watanabe, T. - 1993. Importance of docosahexaenoic acid in marine larval fish. J. World Aquacult. Soc., 24: 152-161.

Watanabe, T., T. Takeuchi, M. Saito and K. Nishimura. - 1984 Effect of low protein-high calorie or essential fatty acid deficiency in diet on reproduction of rainbow trout. Nippon Suisan Gakkaishi, 50: 1207-1215.

Watanabe, T., T. Arakawa, T. Takeuchi and S. Shuichi. - 1989a. Comparison between eicosapentaenoic and docosahexaenoic acids in terms of essential fatty acid efficiency in juvenile striped jack Pseudocaranx dentex. Nippon Suisan Gakkaishi, 55: 1989-1995.

Watanabe, T., M.S. Izquierdo, T. Takeuchi, S. Satoh and C. Kitajima. - 1989b. Comparison between eicosapentaenoic and docosahexaenoic acids in terms of essential fatty acid efficacy in larval red seabream. Nippon Suisan Gakkaishi, 55: 1635-1640.

Watanabe, T., T. Fujimura, M.J. Lee, K. Fukusho, S. Satoh and T. Takeuchi. - 1991. Effect of polar and non polar lipids from krill on quality of eggs of red sea bream Pagrus major. Nippon Suisan Gakkaishi, 57: 695-698.

Zohar, Y., M. Harel, S. Hassin and A. Tandler. - 1995. Gilt-head sea bream. In: N.R. Bromage and R.J. Roberts (eds.): Broodstock management and larval quality, pp. 94-117. Blackwell Science, Oxford.

Scient. ed.: P. Abelló 